\title{
Immunobiology of mild micronutrient deficiencies
}

\author{
P. Bhaskaram \\ National Institute of Nutrition, Indian Council of Medical Research, Jamai-Osmania P.O., \\ Hyderabad-500 007, Andhra Pradesh, India
}

\begin{abstract}
Nutrition is a critical determinant of the outcome of host microbe interactions through a modulation of the immune response. Besides macronutrient malnutrition, deficiencies of several macronutrients also influence immune homeostasis and thus affect infection-related morbidity and mortality. Deficiencies of micronutrients like vitamin A, iron and zinc are widely prevalent among populations living in developing countries. Besides their severe deficiencies, subclinical deficiencies are known to impair biological functions in the host, immune function being one of them. The effects of these micronutrients on various immune mechanisms are briefly reviewed in this article.
\end{abstract}

\section{Zinc: Iron: Vitamin A: Immunity}

Nutrition is a critical factor in modulating immune homeostasis and thereby the outcome of host microbe interactions. Micronutrient deficiencies produce a wide spectrum of effects ranging from clinical disorders due to severe deficiency to subtle functional impairment in subclinical deficiencies which could nevertheless, significantly influence the health and survival of the population. It is now well established that besides protein and energy malnutrition, deficiencies of several micronutrients downregulate immune responsiveness and increase morbidity and mortality due to infections particularly, among children residing in developing countries.

Deficiencies of vitamin A and iron are widely prevalent among preschool children and are important public health problems in most developing countries. Zinc deficiency is believed to be widespread among populations subsisting on cereal based diets due to its poor bioavailability and its effect on the increasing incidence and severity of common childhood infections is becoming apparent.

\section{Vitamin A deficiency}

Besides being an important micronutrient modulating vision, vitamin A has several extra ocular functions (Olson, 1986). Its effects on gene expression influence cellular proliferation and differentiation and glycoprotein synthesis, factors that are important determinants of immune function and epithelial cell integrity.

\section{Vitamin A - immune functions}

Vitamin A deficiency - innate immune mechanisms

Integrity of the epithelial lining of mucosal surfaces with its mucus covering constitutes the major limb of the innate immune responses and is essential to prevent microbial invasion. Loss of integrity of the epithelial lining of mucus membranes in a vitamin A deficient state explains its close association with increased susceptibility to infections particularly of gastrointestinal, respiratory and genitourinary tracts.

Even mild or subclinical vitamin A deficiency induces keratinizing metaplasia of the epithelium and depletes goblet cells from mucosal linings thus causing xerosis of the membranes (Reddy et al. 1989). The xerotic surfaces form potential sites for increased bacterial adherence (Chandra, 1988), thus leading to bacterial colonization.

In the event of systemic invasion by microbes, several humoral and cellular components of the innate immune system get activated and constitute the first order of defence.

The antimicrobial enzyme lysozyme depends on vitamin A for its synthesis. Intracellular lysozyme content has been shown to significantly decline in children suffering from mild xerophthalmia (Mohanram et al. 1974).

Neutrophils and macrophages are phagocytic and bactericidal cells. Increase in respiratory burst on contact of a microbe with the plasma membrane of the phagocytes triggers a series of metabolic events resulting in the production of microbicidal molecules such as $\mathrm{H}_{2} \mathrm{O}_{2}$ and $\mathrm{O}^{2-}$. Studies in experimental vitamin $\mathrm{A}$ deficient rats suggest impairment in the phagocytic cell functions (Ongsakul et al. 1985). However, studies in subclinically vitamin A deficient children (serum retinol $<0.7 \mu \mathrm{mol} / \mathrm{L}$ ) demonstrated no alteration in the bactericidal properties of neutrophils (Bhaskaram et al. 1989a) and in the $\mathrm{IL}_{1}$ production and cytotoxic properties of in vitro activated macrophages (Bhaskaram et al. 1989b). 
Vitamin A deficiency and specific immune functions

Besides the effects on the innate immune system, vitamin A also modulates specific immune mechanisms. Impaired development of primary lymphoid organs and impaired cellular proliferation have been demonstrated in vitamin A deficient chicks. These effects were attributed to impairment of lymphoid cellular proliferation and differentiation of primary lymphoid organs and also to changes in the homing patterns of the cells (Takagi \& Nakano 1983).

Bhaskaram \& Reddy (1975) demonstrated a decrease in T-cell number with no change in proliferative activity in children suffering from mild xerophthalmia due to vitamin A deficiency. Further, decrease in the proportions of T-cell subpopulations have been documented in children having vitamin A deficiency (Bhaskaram, 1989; Semba et al. 1993). It is known that vitamin A deficiency affects epithelial cells as clinical lesions become apparent. It is possible that vitamin A deficiency by compromising thymic epithelial integrity might reduce thymulin secretion resulting in these changes. This effect was reversible with adequate vitamin A supplementation. However, mild vitamin A deficiency in children does not appear to have significant effects on humoral immune mechanisms. Antibody titres mounted on challenge with diphtheria and tetanus and typhoid vaccines have been found to be unaltered (Bhaskaram et al. 1989a). Kutty et al. (1981) demonstrated no change in the circulating B-cell number in children with mild vitamin A deficiency.

\section{Vitamin A deficiency - infections}

Association of infectious diseases and severe vitamin A deficiency has been well established in both experimental animals (Darip et al. 1979) and children with keratomalacia (McLaren et al. 1965). These studies demonstrate close association between severe vitamin A deficiency and infection but not necessarily evidence of a causal relationship between the two due to possible confounding influences of other variables particularly, in the human studies. Severe single nutrient deficiencies are rare in humans unlike in experimental situations. Particularly, severe vitamin A deficiency is always associated with severe protein energy malnutrition that also causes immunosuppression. Hence extrapolation of results obtained from experimental studies may not be valid for humans.

However, Sommer et al. (1984) reported increase in the relative risk of death in Indonesian children having evidence of mild xerophthalmia. In a subsequent report the same group of investigators reported reversal of these effects following vitamin A administration (Sommer et al. 1986). These observations attribute a causal role for vitamin A to increase morbidity and mortality due to infections. This striking observation has triggered a global debate on the role of vitamin A in child survival and led to intervention trials in preschool children in a number of countries under heterogeneous conditions with regard to the vitamin A status, culture, ecology and disease pattern. The results of a meta-analysis of eight major mortality intervention trials (Beaton et al. 1993) indicated an overall reduction of mortality rate by $23 \%$ with vitamin $\mathrm{A}$ supplementation. Impact of vitamin A was more consistently appreciated with measles (Sommer \& West, 1996) and diarrhoea (Barreto et al. 1994) rather than on respiratory tract infections in lowering the morbidity and mortality. Though vitamin A deficiency has been associated with acute respiratory infections (Sommer et al. 1984), Stephensen et al. (1997) reported the impact of vitamin A intervention on respiratory morbidity could be equivocal or even adverse. Herrera et al. (1996), however, reported from a large hospital based clinical study that vitamin A had a marginal effect on the severity of the infections, if not on duration. An increase in coughs observed among the supplemented children was however, interpreted as a beneficial response.

The mechanisms involved in these varying outcomes of vitamin A supplements on intestinal and respiratory mucosa are not clearly understood. It is possible that the differences in the milieu to which the mucosal cells of these two systems are exposed and a number of other systemic and environmental factors governing the local tissue response and factors influencing the local mucosal immune response might be the critical determinants of the outcome of intervention.

Irrespective of the mechanism of action, the results of vitamin A supplementation on respiratory morbidity raise concern about vitamin A supplementation programmes implemented in communities with widely prevalent vitamin A deficiency often co-existing with recurrent respiratory infections in children.

\section{Effect of large dose vitamin A}

The immune adjuvant functions of vitamin A are well established. Children receiving 100000 to 200000 IU of $\mathrm{RE}$ as a single oral dose were observed to have enhanced phagocytic functions with increase in hydrogen peroxide production by neutrophils. Macrophage functions measured by interleukin 1 production and cytotoxicity were also enhanced. A significant increase in antibody titres to specific antigens like diphtheria and tetanus and typhoid vaccine was also observed (Bhaskaram et al. 1989a). Similar observations have also been reported from Bangladesh by Rahman et al. (1999). These immune potentiating effects were observed even in healthy children whose serum retinol levels were more than $0.7 \mu \mathrm{mol} / \mathrm{L}$ (Bhaskaram et al. 1989a).

Co-administration of vitamin A with measles vaccine has been documented to significantly improve seroconversion rates in 9-month-old infants when maternal antibody titres are low or absent (Benn et al. 1997). This effect is evident particularly when seroconversion rate to measles vaccine in routine immunization programmes is low as observed in tropical countries like India (Bhaskaram \& Rao, 1997). Semba et al. (1997) however, found no enhancement of seroconversion rates in 9-month-old Indonesian infants whose basal seroconversion rates were already optimal. However, similar potentiating effects of vitamin A administration were not observed on oral polio vaccine (OPV) immunogenicity when it was administered to young infants (Bhaskaram \& Balakrishna, 1998; Bahl et al. 1999). It may 
be interesting to determine if maternal antibodies in the newborns and young infants explain the lack of an enhancing effect on OPV immunogenicity. Nevertheless, these reports, which clearly indicate no adverse effects of combining administration of vitamin A with live attenuated viral vaccines, are particularly of significance at a time when the safety of such a combined strategy is being questioned.

The immuno-potentiating effects of vitamin A and its related compounds have been exploited in treating immuno-compromised states like burns and surgical conditions (Fusi et al. 1984; Cohen et al. 1979).

\section{Vitamin A - infection and immunity in pregnancy}

Recent studies have highlighted the significant role of vitamin A in pregnant women. Christian et al. (1998) from Nepal reported a higher frequency of urinary, reproductive tract and gastrointestinal infections in pregnant women of low vitamin A status. Higher rate of vertical transmission of the disease (Semba et al. 1994) and higher rate of vaginal shedding of infected cells (Mostad et al. 1997) in pregnant women positive for HIV-1 virus and having low serum retinol levels thus threatening the infant survival have been reported. The investigators speculated that several factors like altered maternal immune function due to the combined effects of vitamin A deficiency and HIV -1 infection in pregnancy with consequent increase in viremia, impaired epithelial integrity of the lower reproductive tract, and a possibly compromised placental function may have been responsible for the high rate of infection of the babies either in utero or during labour. Viral excretion in breast milk could be an added risk for breast-fed infants.

Apart from the role of vitamin A deficiency in increasing the morbidity in pregnant women, West et al. (1999) in a double blind randomised trial in Nepal, reported that administration of vitamin $\mathrm{A}$ or $\beta$-carotene supplements led to a $44 \%$ reduction in maternal deaths related to pregnancy and early postpartum period. This study invited substantial criticism and serious concern was expressed particularly regarding the causes of maternal deaths that were prevented by the intervention, as well as the ethical issues concerning the administration of $7000 \mu \mathrm{g}$ of retinol once a week during pregnancy. These results need confirmation in other situations using appropriate experimental design.

\section{Iron deficiency}

Iron deficiency anaemia affects all age groups of the under privileged population in most developing countries. Even among affluent families, specific age groups like adolescent girls and the elderly suffer from this nutrient deficiency. Due to its serious functional effects, iron deficiency anaemia in the vulnerable groups namely pregnant women and preschool children is of public health significance in developing countries. Besides anaemia, subclinical iron deficient status also influences several physiological functions that govern cellular proliferation and metabolism. The significant association of iron deficiency anaemia with infection demonstrated by epidemiological and clinical studies has been extensively reviewed (Bhaskaram, 1988) and the effects attributed to the adverse effects of iron deficiency on the immune system. Reversal of the clinical and immunological defects by iron administration in iron deficient adults suffering from muco-cutaneous candidiasis convincingly demonstrates the casual role for iron in increasing susceptibility to infections (Chandra \& Vyas, 1984).

Severe iron deficiency anaemia has been shown to impair cellular immune functions which reverted to normal following correction of the deficiency (Chandra \& Saraya, 1975; MacDougall et al. 1978). In a subsequent study by Srikantia et al. (1976), Indian children suffering from moderate to severe anaemia $(<100 \mathrm{~g} / \mathrm{L})$ were found to have impaired neutrophil bactericidal activities and cell mediated immune functions which were reversible with adequate iron therapy (Bhaskaram et al. 1977). Prasad (1980) demonstrated a decrease in halogenation of phagocytosed particles in neutrophils in iron deficient individuals, a function that is carried out by the iron dependent myeloperoxidase enzyme which constitutes a powerful bactericidal system in neutrophils in the presence of $\mathrm{H}_{2} \mathrm{O}_{2}$ and halide ions. Impaired cell mediated immune functions have also been demonstrated in anaemic pregnant women (Prema et al. 1982). Sipahi et al. (1998) observed circulating $\mathrm{IL}_{2}$ levels to be low in children suffering from iron deficiency anaemia. In confirmation with the previous study, recent studies from the National Institute of Nutrition, Hyderabad, India (unpublished) demonstrated polarization of $\mathrm{T}$-lymphocyte subsets to $\mathrm{Th}_{2}$ population with predominant $\mathrm{IL}_{4}$ mRNA expression with no $\mathrm{IL}_{2}$ expression in anaemic children unlike the normals in whom both $\mathrm{IL}_{2}$ and $\mathrm{IL}_{4}$ were expressed. This polarization can interfere with resistance to infections particularly due to intracellular pathogens and also response to certain vaccines. The irreversible effect of maternal anaemia on the immune functions of the offspring observed in the experimental animals (Kochanowski \& Sherman, 1983) is a further cause for concern in populations with high prevalence of iron deficiency in pregnancy.

\section{Zinc deficiency}

The extent of zinc deficiency has not been precisely quantified among populations because of lack of a simple and sensitive tool to measure zinc status. Nevertheless, the low bioavailability of zinc from cereal-based staple diets of populations in most of the developing countries has led to the presumption that mild or subclinical zinc deficiency could be widespread in such populations.

\section{Zinc - infectious diseases}

The close association between zinc deficiency and increased diarrhoeal and respiratory morbidity has been demonstrated (Bhandari et al. 1996; Bahl et al. 1998). Several investigators have demonstrated a significant and consistent reduction in the severity and duration of diarrhoea following zinc administration particularly, when it is prolonged (Roy et al. 1999; Penny et al. 1999; Sazawal et al. 1997a; Sazawal et al. 1995) by supplementing with 
zinc in varying doses. Further, Ruel et al. (1997) from Guatemala documented significant reduction of acute respiratory infections following zinc supplementation in children. Sempertegui et al. (1996) documented the usefulness of zinc supplements to reduce respiratory tract infections in malnourished children. These beneficial effects observed with zinc supplements on both diarrhoeal and respiratory morbidity have practical significance and suggest that zinc supplements may complement the effects of vitamin A in reducing over all morbidity burden due to infections in populations having both these micronutrient deficiencies. However, there is a need to establish the safety of zinc supplementation in communities where other trace metal deficiencies are equally widespread as prolonged zinc administration is known to interfere with the absorption of copper, iron and calcium.

Zinc supplements were also found to be beneficial in the elderly (Mocchegiani et al. 1999) in reducing opportunistic infections by preventing reduction in $\mathrm{CD}_{4}^{+}$cells. Due to similar immune effects, it has also been demonstrated to be useful as an adjunct to chemotherapy in individuals suffering from acquired immune deficiency syndrome (AIDS) (Mocchegiani et al. 1995). The effects of zinc on infectious diseases may be attributed to its effects on varied immune functions. However, it is not clear whether these actions of zinc on infections and immune functions are brought about by correcting the existing zinc deficiency or by pharmacological actions.

\section{Zinc and immune function}

Zinc is essential for DNA synthesis and is a co-factor for several enzymes including thymulin which regulates the intrathymic differentiation and maturation of T-lymphocytes. Beck et al. (1997) observed decrease in $\mathrm{Th}_{1}$ cytokines with no change in $\mathrm{Th}_{2}$ cytokines thus causing an imbalance between $\mathrm{Th}_{1}$ and $\mathrm{Th}_{2}$ responses in experimentally induced zinc deficiency in humans. Zinc was shown to expand the $\mathrm{IL}_{2}$ (interleukin 2) producing lymphocyte population in in vitro studies (Saha et al. 1995). Sazawal et al. (1997b) reported a significant increase in $\mathrm{CD}_{3}, \mathrm{CD}_{4}$ lymphocyte populations with an increase in $\mathrm{CD}_{4}: \mathrm{CD}_{8}$ ratio following zinc supplementation in children.

Besides these effects of zinc on cell mediated immune responses, its role in modulating phagocyte and NK cell activity are well described. Fan et al. (1996) observed that impaired leucocyte adhesion and lymphocyte function in zinc deficient premature infants were reversed following zinc therapy. Abul et al. (1995) documented the regulatory role of zinc on the production of IL-1 $\alpha$ from alveolar macrophages of patients with acute lung disease. In addition to these effects, zinc supplements lead to accelerated regeneration of mucosa, increase in the levels of brush border enzymes, enhanced cellular immunity and higher level of secretory antibodies as documented by Folwaczny et al. (1997). These varied and protective immunological functions of zinc perhaps explain its effects in significantly reducing infectious illness particularly those of mucosal tracts.

\section{Antioxidant micronutrient deficiency}

A number of micronutrients like $\beta$ carotene, vitamin $C$, selenium, copper and others are powerful antioxidants and have a significant impact on infection related morbidity in humans. Oxidant stress has been demonstrated to have impact on viral infections. By influencing the cytokine profile of T-cells and also by inducing genomic alterations in the viruses, oxidant stress plays a role in enhancing the pathogenesis of a virus or leads to the emergence of new pathogenic viral strains. Deficiency of dietary antioxidants increases this risk (Beck \& Levander, 1998). This could be a potentially serious threat particularly, in the micronutrient deficient developing countries.

\section{Conclusions}

Micronutrient deficiencies are of clinical and public health magnitude in developing countries and account for significant morbidity and mortality due to infections. Vitamin A, zinc and iron, the micronutrients of clinical and public health significance have immunomodulatory effects by influencing a wide range of immune mechanisms in humans. Though the effects of single micronutrients are well established in experimental animals, such isolated deficiencies are uncommon in humans. The complex interactions of several coexisting nutritional deficiencies particularly of trace metals warrant studies to establish the bioeffects and cost effectiveness of providing single nutrient supplements vis-à-vis multinutrient supplements. Defining the precise extent of the problem contributed by deficiency of each micronutrient is essential though challenging. The untoward effects that follow prolonged single nutrient supplements (e.g. prolonged zinc supplements on the nutrients like copper, calcium and iron) need to be explored and the ethical issues concerning single nutrient supplements to populations having multiple deficiencies critically addressed.

Though this article highlights only the immunobiology of some commonly deficient micronutrients, it is needless to mention that several other micro and macronutrient deficiencies could be concomitantly present in the underprivileged populations with several other functional deficits which need correction together to achieve significant effects on the overall health of the population rather than promoting mere survival.

\section{References}

Abul HT, Abul AT, al-Athary EA, Behbehani AE, Khadadah ME \& Dashti HM (1995) Interleukin-1 alpha (IL-1 alpha) production by alveolar macrophages in patients with acute lung diseases: the influence of zinc supplementation. Molecular and Cell Biochemistry 146, 139-145.

Bahl R, Bhandari N, Hambidge KM \& Bhan MK (1998) Plasma zinc as a predictor of diarrhoeal and respiratory morbidity in children in an urban slum setting. American Journal of Clinical Nutrition 68 (Suppl), 4145-4175.

Bahl R, Bhandari N, Kant S \& Bhan MK (1999) Vitamin A administered with oral polio vaccine does not alter immunogenecity. In XIX IVACG Meeting, Vitamin $A$ and other micronutrients, Durban, South Africa, 33 
Barreto ML, Santos LMP, Assis AMO, Araujo MPN, Farenzena GG, Santos PAB \& Fiaccone LL (1994) Effect of vitamin A supplementation on diarrhoea and acute lower respiratory tract infections in young children in Brazil. Lancet 344, 228-231.

Beaton GH, Martorell R, Aronson KJ, Edmonston B, McCabe G, Ross AC \& Harvey B (1993) Effectiveness of vitamin A supplementation in the control of young child morbidity and mortality in developing countries. ACC/SCN State of the Art Series, Nutrition Policy Discussion paper No. 13, United Nations, Geneva

Beck MA \& Levander OA (1998) Dietary oxidative stress and potentiation of viral infection. In Annual Reviews of Nutrition, 18, pp. 93-116 [DB McCormick editor, DM Bier and AG Goodridge, associate editors]. Palo Alto, CA

Beck FW, Prasad AS, Kaplan J, Fitzerald JT \& Bremer GJ (1997) Changes in cytokine production and T-cell subpopulations in experimentally induced zinc-deficient humans. American Journal of Physiology 272, 1002-1007.

Benn CS, Aaby P, Bale C, Olsen J, Michaelsen KF, George E \& Whittle W (1997) Randomised trials of effect of vitamin A supplementation on antibody response to measles vaccines in guinea - Bissau. West Africa. Lancet 350, 101-105.

Bhandari N, Bahl R, Hambidge KM \& Bhan MK (1996) Increased diarrhoeal and respiratory morbidity in association with zinc deficiency - a preliminary report. Acta Paediatrica 85, 148150.

Bhaskaram C \& Reddy V (1975) Cell mediated immunity in iron and vitamin A deficient children. British Medical Journal 3, 522.

Bhaskaram P, Prasad JS \& Krishnamachari KAVR (1977) Anaemia and immune response. Lancet 1, 1000.

Bhaskaram P (1988) Immunology of iron deficient subjects in contemporary issues in clinical nutrition. In Nutrition and Immunology, pp. 149-68 [RK Chandra, editor]. New York, NY: Alan R Liss Inc.

Bhaskaram P, Jyothi SA, Rao KV \& Rao BSN (1989a) Effect of subclinical vitamin A deficiency and administration of vitamin A as a single oral dose on immune function in children. Nutrition Research 9, 1017-1025.

Bhaskaram P, Sharada K, Sivakumar B, Rao KV \& Nair KM (1989b) Effect of iron and vitamin A deficiencies on macrophage function in children. Nutrition Research 9, 35-45.

Bhaskaram P (1989) Infection and immunity of vitamin A and iron deficient children in: Child Nutrition in South East Asia. Eighth Nutricia Symposium, pp. 185-197 [KHA Visses and JG Bindels, editors]. Dordrecht, Netherlands: Kluwer Academic Publishers.

Bhaskaram P \& Rao KV (1997) Enhancement of seroconversion on simultaneous administration of measles vaccine and vitamin A to 9 months old Indian infants. Indian Journal of Pediatrics 64, 503-509.

Bhaskaram P \& Balakrishna N (1998) Effect of administration of $200000 \mathrm{IU}$ of vitamin A to women $24 \mathrm{hrs}$ after delivery on response to OPV administration to newborn. Indian Paediatrics 35, 2317-2322.

Chandra RK \& Saraya AK (1975) Impaired immunocompetence associated with iron deficiency. Paediatrics 86, 899-902.

Chandra RK \& Vyas D (1984) Functional consequences of iron deficiency, non-erythroid effects. In Critical Reviews in Tropical Medicine, 2, p. 93 [RK Chandra, editor]. New York, NY: Plenum Press.

Chandra RK (1988) Increased bacterial binding to respiratory epithelial cells in vitamin A deficiency. British Medical Journal 297, 834-835.

Christian P, Schulze K, Stolzfus RJ \& West KP Jr (1998) Hyporetinolemia, illness symptoms and acute phase protein response in pregnant women with and without night blindness. American Journal of Clinical Nutrition 67, 1237-1243.

Cohen BE, Gill G, Culler PR \& Morris PJ (1979) Reversal of postoperative immunosuppression in man by vitamin A. Surgery Gynecology and Obstetrics 149, 658-662.

Darip MD, Sirisinha S \& Lamb AJ (1979) Effect of vitamin A deficiency on susceptibility of rats to Angiostrongylus canotonesis (40605). Proceedings of the Society of Experimental Biology and Medicine 161, 600-604.

Fan PC, Teug RJ, Chou CC, Wu TJ, Tsou Yau KI \& Hseih KH (1996) Impaired immune function in a premature infant with zinc deficiency after total parenteral nutrition. Chung Hua Min Kuo Hsiao Erh KoI Hsueh HUI Tsa Chih 37, 64-69.

Folwaczny C, Medizinische K \& Klinikum I (1997) Zinc and diarrhoea in infants. Journal of Trace Elements, Medicine and Biology 11, 116-122.

Fusi S, Kupper TS, Green DR \& Ariyan S (1984) Reversal of postburn immunosuppression by administration of vitamin A. Surgery 96, 330-335.

Herrera MG, Fawzo WW \& Nestel P (1996) Effect of vitamin A supplementation on the incidence of cough, diarrhea and fever. XVII IVACG meeting report, Guatemala City, 95

Kochanowski BA \& Sherman AR (1983) Decreased antibody formation of iron deficient rat pups - effect of iron repletion. American Journal of Clinical Nutrition 41, 278-284.

Kutty PM, Mohanram M \& Reddy V (1981) Humoral immune response in vitamin A deficient children. Acta Vitaminol Enzymol 3, 231-235.

MacDougall LG \& Jacobs MR (1978) The immune response of iron deficient children. South African Medical Journal 53, 405407.

McLaren DS, Shirajan E, Techalian H \& Khoury G (1965) Xeropthalmia in Jordon. American Journal of Clinical Nutrition 17, 117-130.

Mocchegiani E, Veccia S, Ancarani F, Scalise G \& Fabris N (1995) Benefit of oral zinc supplementation as an adjunct to zidovudine (AZI) therapy against opportunistic infections in AIDS. International Journal of Immunopharmacology 17, 719727.

Mocchegiani E, Muzzioli M, Gaetti R, Veccia S, Viticchi C \& Scalise G (1999) Contribution of zinc to reduce CD4+ risk factor for 'severe' infection relapse in aging: parallelism with HIV. International Journal of Immunopharmacology 21, 271281.

Mohanram M, Reddy V \& Mishra S (1974) Lysozyme activity in plasma and leucocytes in malnourished children. British Medical Journal 32, 313-316.

Mostad SB, Overbaugh J, DeVange DM, Welch MJ, Chohan B, Mandaliya K, Nyange P, Martin HL Jr, Ndinya-Achola J Bwayojj \& Kreiss JK (1997) Hormonal contraception, vitamin A deficiency and other risk factors for shedding of HIV-1 infected cells from the cervix and vagina. Lancet 350, 922-927.

Olson JA (1986) Physiological and metabolic basis of major signs of vitamin A deficiency. In Vitamin A Deficiency and its Control, pp. 19-67 [JC Bauernfeind, editor]. New York, NY: Academic Press Inc.

Ongsakul M, Sirisinha S \& Lamb AJ (1985) Impaired blood clearance of bacteria and phagocytic activity in vitamin A deficient rats (41999). Proceedings of Experimental Biology and Medicine 178, 204-208.

Penny ME, Peerson JM, Marin RM, Duran A, Lanada CF, Lonnerdal B, Black RE \& Brown KH (1999) Randomized, community based trial of the effect of zinc supplementation with and without other micronutrients on the duration of persistent childhood diarrhoea in Lima, Peru. Journal of Pediatrics 135, 208-217. 
Prasad JS (1980) Leukocyte function in iron-deficiency anaemia. American Journal of Clinical Nutrition 32, 550-552.

Prema K, Ramalakshmi BA, Madhavapeddi R \& Babu S (1982) Immune status of anaemic pregnant women. British Journal of Obstetrics and Gynaecology 89, 222-225.

Rahman MM, Mahalanabis D, Hossain S, Wahesd MA, Fuchs GJ, Alvarez JO, Thompson C, Siber GR \& Santosham M (1999) Vitamin A administration with immunization enhances antibody response to diphtheria vaccine. Report of the XIX IVACG Meeting, Vitamin A and other micronutrients, Durban, South Africa, T24, 79.

Reddy V, Rao VM, Jyothi A \& Reddy M (1989) Conjunctival impression cytology for assessment of vitamin A status. American Journal of Clinical Nutrition 50, 814-817.

Roy SK, Tomkins AM, Haider R, Behren RH, Akramuzzaman SM, Mahalanabis D \& Fuchs GJ (1999) Impact of zinc supplementation on subsequent growth and morbidity in Bangladeshi children with acute diarrhoea. European Journal of Clinical Nutrition 53, 529-534

Ruel MT, Rivera JA, Santizo MC, Lonnerdal B \& Brown KH (1997) Impact of zinc supplementation on morbidity from diarrhoea and respiratory infections among rural Guatemalan children. Paediatrics 99, 808-813.

Saha AR, Hadden EM \& Hadden JW (1995) Zinc induces thymulin secretion from human thymic epithelial cells in vitro and augments splenocyte and thymocyte responses in vivo. International Journal of Immunopharmacology 17, 729-733.

Sazawal S, Black RE, Bhan MK, Bhandari N, Sinha A \& Jalla S (1995) Zinc supplementation in young children with acute diarrhoea in India. New England Journal of Medicine 333, 839-844.

Sazawal S, Black RE, Bhan MK, Jalla S, Sinha A \& Bhandari N (1997a) Efficacy of zinc supplementation in reducing the incidence and prevalence of acute diarrhoea - a community based double blind controlled trial. American Journal of Clinical Nutrition 66, 413-418.

Sazawal S, Jalla S, Muzumder S, Sinha A, Black RE \& Bhan MK (1997b) Effect of zinc supplementation on cell mediated immunity and lymphocyte subsets in preschool children. Indian Pediatrics 34, 589-597.

Semba RD, Muhilal, Ward BJ, Griffin DE, Scott AL, Natadisastra G, West KP Jr \& Sommer A (1993) Abnormal T-cell subset proportions in vitamin A deficient children. Lancet 341, 5-8.
Semba RD, Miotti PG, Chiphanguwi JD, Saah AJ, Canner JK \& Dallabetta GA (1994) Maternal vitamin A deficiency and mother to child transmission of HIV-1. Lancet 343, 1593-1597.

Semba RD, Akeb A, Beeler J, Munasis Z, Permaesin D, Muherdiyantiningsih , Komala , Maruti S \& Muhilal (1997) Effect of vitamin A supplementation on measles vaccines in 9 month old infants. Public Health 111, 247-247.

Sempertegui F, Estrella B, Correa E, Agwirre L, Saa B, Torres M, Navarrete F, Alarcon C, Carrion J, Rodriguez \& Griffiths JK (1996) Effects of short-term zinc supplementation on cellular immunity, respiratory symptoms, and growth of malnourished Equadorian children. European Journal of Clinical Nutrition 50, 42-46.

Sipahi T, Akar N, Egin T \& Cin S (1998) Serum interleukin-2 and interleukin-6 levels in iron deficiency anaemia. Pediatric Hemotology and Oncology (England) 15, 69-73.

Sommer A, Katz J \& Tarwotjo I (1984) Increased risk of respiratory disease and diarrhoea in children with preexisting mild vitamin A deficiency. American Journal of Clinical Nutrition 40, 1090-1095.

Sommer A, Tarwotjo I, Djunaedi E, West KP Jr, Loeden AA, Tilden R \& Mele LAceh study group (1986) Impact of vitamin A supplementation on childhood mortality. A randomised community trial. Lancet 1, 1169-1173.

Sommer A \& West KP Jr (1996) Vitamin A deficiency. In Health, Survival and Vision. New York, NY: Oxford University Press.

Srikantia SG, Prasad JS, Bhaskaram C \& Krishnamachari KAVR (1976) Anaemia and immune response. Lancet 1, 1307-1309.

Stephensen CB, Franchi LM, Hernandez H, Campos M, Gilman RH \& Alvarez JO (1997) A randomized placebo-controlled double-blind clinical trial of high-dose vitamin A supplements in children hospitalized with pneumonia in Lima, Peru. In sustainable control of vitamin A deficiency. Report of the XVIII International Vitamin A Consultative Group Meeting, Cairo, Egypt, 102

Takagi H \& Nakano K (1983) The effect of vitamin A depletion on antigen-stimulated trapping of peripheral lymphocytes in local lymph nodes of the rat. Immunology 48, 123-128.

West KP Jr, Katz J, Khatry SK, Lecler SE, Pradhan EK, Srestha SR, Connor PB, Dali SM, Christian P, Pokhrel RP \& Sommer A (1999) Double blind cluster randomised trial of low dose supplementation with vitamin $A$ or $\beta$ carotene on mortality related to pregnancy in Nepal. British Medical Journal 7183, 570-575. 